\title{
UNIVERSITY OF KENTUCKY \\ College of Medicine
}

\section{Infectious Diseases Division Chief}

Outstanding opportunity for a dynamic Infectious Disease specialist. The Department of Internal Medicine at the University of Kentucky is seeking a physician to fulfill the position of Chief in the Division of Infectious Disease. Minimum requirements for this position include Associate Professor, Board certified in Internal Medicine and Infectious Diseases with experience in epidemiology and infection control. This academic leader will be directing a Division of 10 faculty, and act as director of Infection Control for our University Hospital. This exciting academic opportunity presents as our Medical Center is expanding and constructing an 800 Patient Bed Tower. The University of Kentucky is a well recognized leading Regional referral center.

Interested individuals should send a CV and the names of three references to:

Frederick C. de Beer, M.D.

Chairman, Department of Internal Medicine

University of Kentucky

740 S. Limestone St., Rm. J-525

Lexington, KY 40536-0284

Email: fcdebe $1 @$ uky.edu

Electronic submissions of CV's and references are encouraged. If offered this position, you will be required to pass a pre-employment drug screen as required by University of Kentucky Human Resources.

\section{see blue.}

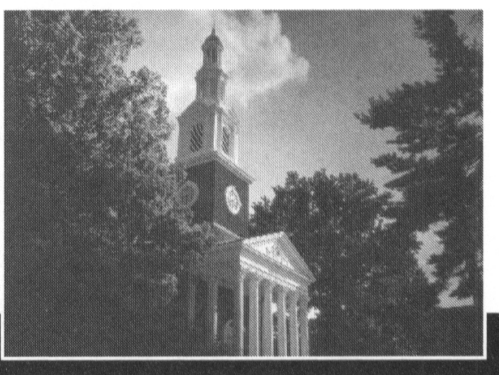

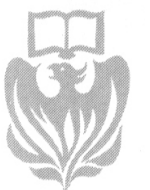

CHICAGO JO

JOURNALS

\section{EDUCATION}

Signs

Social Service Review

Supreme Court Economic Review

The Supreme Court Review

\section{HUMANITIES}

American Art

Classical Philology

Critical Inquiry

Ethics

History of Religions

International Journal of American Linguistics

Journal of Near Eastern Studies

The Journal of Religion

Modern Philology

Signs

Winterthur Portfolio

\section{PHYSICAL SCIENCES}

The Astrophysical Journal

The Astrophysical Journal

Supplement Series

The Journal of Geology

Publications of the Astronomical

Society of the Pacific
American Journal of Education Comparative Education Review The Elementary School Journal

\section{BIOLOGICAL AND HEALTH SCIENCES}

The American Naturalist Clinical Infectious Diseases Infection Control and Hospital Epidemiology

International Journal of Plant Sciences

The Journal of Infectious Diseases

Physiological and Biochemical Zoology

The Quarterly Review of Biology

U B L I S H E D B Y

THE UNIVERSITY

OF CHICAGO PRESS

JOURNALS DIVISION

\section{Osiris}

Philosophy of Science 


\section{ADVERTISING 2008 \\ Recruitment Advertising \\ INFECTION CONTROL \& HOSPITAL EPIDEMIOLOGY}

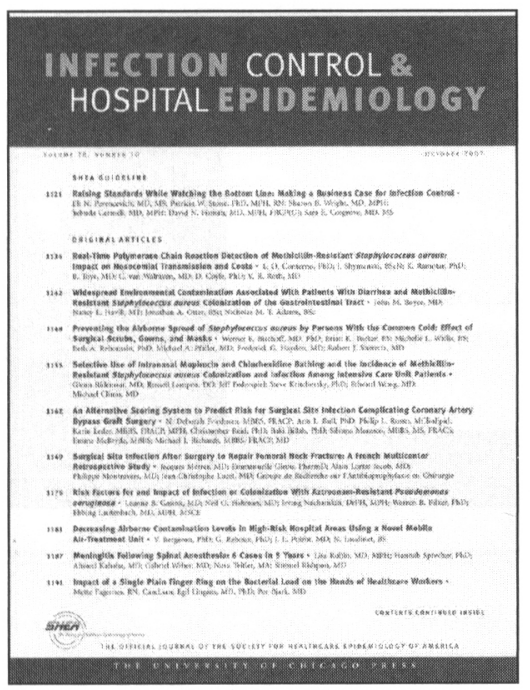

\section{Advertising Rates:}

$\begin{array}{lll}\text { Full Page } & 73 / 4 " \times 103 / 8 " & \$ 719^{*} \\ \text { Vert Half } & 31 / 2 " \times 103 / 8 " & \$ 551^{*} \\ \text { Hori Half } & 73 / 4 " \times 53 / 16 " & \$ 551^{*} \\ \text { Trim Size } & 81 / 4 " \times 107 / 8 " & \end{array}$

* denotes net rate, noncommissionable.

Rates apply to Recruitment Advertising only. Additional \$50 to typeset/design half page ad; $\$ 100$ for full page ad.

\section{Advertising Deadlines:}

\begin{tabular}{ll||ll}
\hline Issue & Space \& Art & Issue & Space \& Art \\
January & December 3 & July & May 28 \\
February & January 3 & August & July 2 \\
March & January 30 & September & July 31 \\
April & March 3 & October & September 3 \\
May & March 27 & November & October 1 \\
June & May 1 & December & October 29
\end{tabular}

For recruitment as well as commercial advertising information please email Tim Hill at thill@press.uchicago.edu; phone 773.702.8187; fax 773.702.0172.

*Please note: Commercial Advertising rates apply to Conference and Publisher Advertising

\section{CHICAGO JOURNALS}




\section{Clinical}

Infectious

Diseases

Official publication of the Infectious Diseases Society of America

Clinical Infectious Diseases (CID) publishes topical research and incisive commentaries from distinguished clinicians and scientists on the diagnosis and treatment of infectious diseases. Each issue contains clinically relevant articles of current interest in:

- Clinical research

- Immune mechanisms

- Medical microbiology

- Epidemiology and prevention

- Pathogenesis

- HIVIAIDS

- New antimicrobial therapies

\section{CID Online}

Read a sample issue, sign up for RSS feeds, register for e-mail tables of contents alerts, and use UpToDate, the free "topic link" information service - all online at www.journals.uchicago.edu/CID.

\section{To Subscribe:}

Phone: (877) 705-1878 (USA/Canada) (773) 753-3477 (International)

Fax: (877) 705-1879 (USA/Canada) (773) 753-0811 (International)

Online: www.journals.uchicago.edu/CID E-mail: subscriptions@press.uchicago.edu

\section{墨IDSA}

Providing Timely Information on Clinical Topics and Infectious Disease Research

Editor, Sherwood L. Gorbach

Tufts University School of Medicine

\section{s}

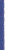

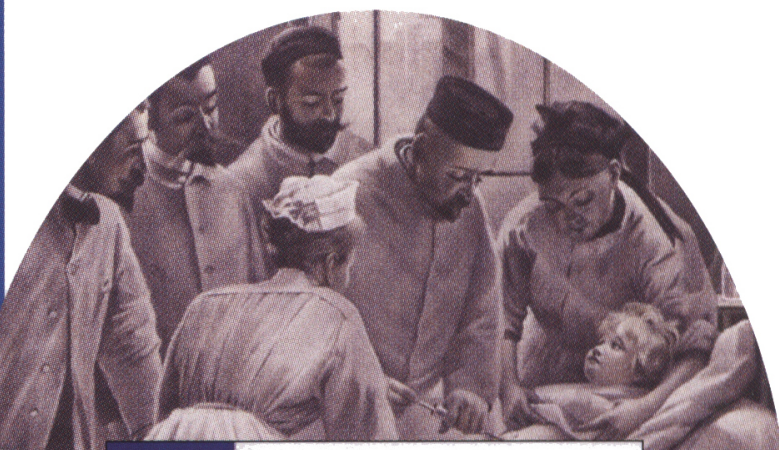

Clinical Infectious Diseases

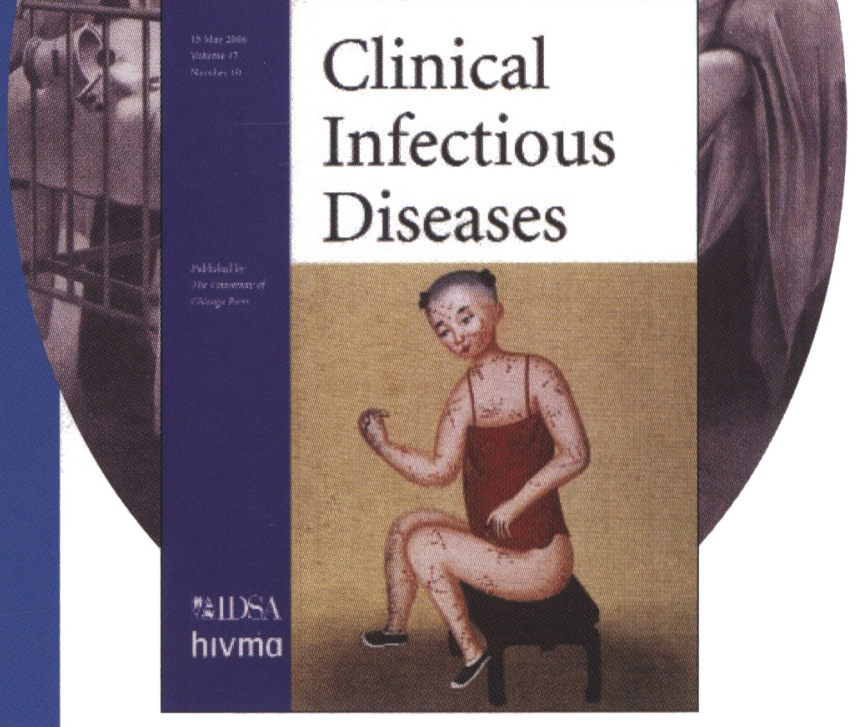

Semimonthly. ISSN: 1058-4838.

THE UNIVERSITY

OF CHICAGO PRESS

JOURNALS DIVISION

www.journals.uchicago.edu 


\section{Clinically proven to reduce incidence of CRBSI by}

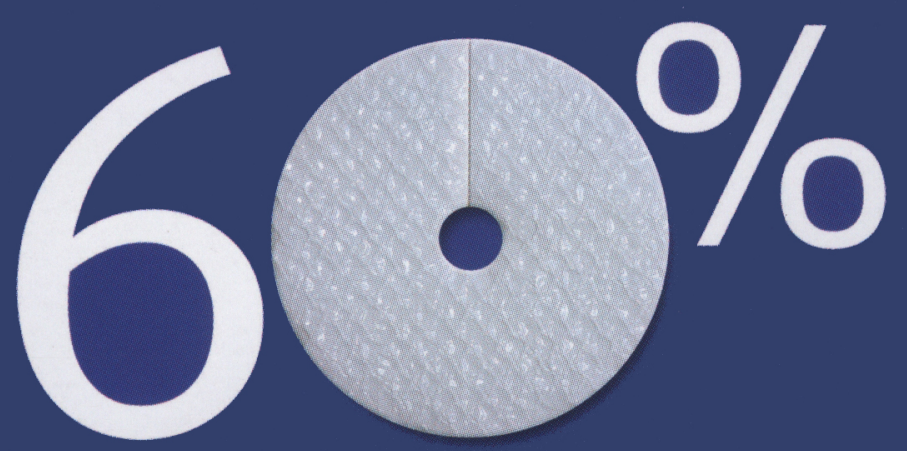

You strive to ensure your patients recover quickly. However, Catheter-Related Bloodstream Infections (CRBSI) can set that recovery back while increasing risk of mortality., ${ }^{1,2}$ Only BIOPATCH ${ }^{\circledR}$ Protective Disk with CHG is proven to reduce incidence of CRBSI by $60 \%$ and local infections by $44 \%$. The proprietary technology in BIOPATCH ${ }^{\circledR}$ continually releases CHG over seven days for sustained antimicrobial action. So when you use BIOPATCH${ }_{1}^{\circledast}$ you know you are doing everything possible to prevent CRBSI. For additional information or technical support, call 877-ETHICON. For full Prescribing Information, and to order, visit WWW.BIOPATCH.COM, or call 800-255-2500.

\section{Gohnsonatfohnson

\section{BIOPATCH}

\author{
Protective Disk with CHG
}

References: 1. Maki DG, Mermel L, Genthner D, Hua S, Chiacchierini RP. An evaluation of BıoPATCH Antimicrobial Dressing compared to routine standard of care in the prevention of catheter-related bloodstream infection. Johnson \& Johnson Wound Management, a division of ETHICON, INC. 2000. Data on file. 2. Crawford AG, Fuhr JP Rao B. Cost-Benefit Analysis of Chlorhexidine Gluconate Dressing in the Prevention of Catheter-Related Bloodstream Infections. Infect Control and Hosp Epidemiol. 2004:25:668-674 